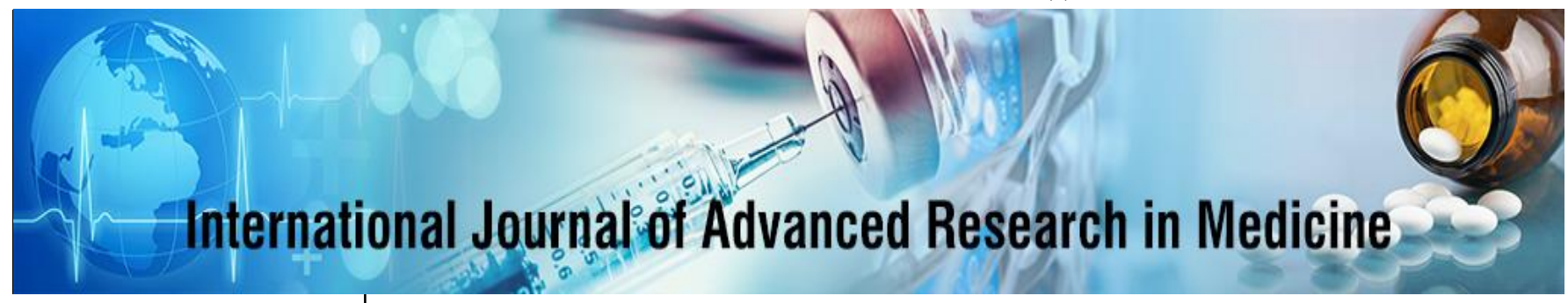

E-ISSN: 2706-9575

P-ISSN: 2706-9567

IJARM 2021; 3(2): 552-556

Received: 04-07-2021

Accepted: 06-09-2021

Dr. Marab Younis Abdullah AlFathy

MCHB, M Sc, Ph.D.

Community Medicine,

Nineveh Health Directorate

Department of Training and

Human Development Center.

Specialist Community,

Al-Seedek / Mosul City, Iraq

Dr. Muna Muneer Ahmed Lecturer, Bacalor M Sc.

Administration and Economics (Statistician), College of Medicine, Mosul University, Department of Family and

Community Medicine Al-

Malyia, Mosul City, Iraq

Dr. Nahla Khalaf Ali MCHB, Diploma Community Medicine, Nineveh Health Directorate, Department of Training and Human Development Center, Specialist Community Medicine, Al- Andalus, Mosul City, Iraq
Corresponding Author:

Dr. Marab Younis Abdullah AlFathy

MCHB, M Sc, Ph.D.

Community Medicine,

Nineveh Health Directorate

Department of Training and

Human Development Center.

Specialist Community,

Al-Seedek / Mosul City, Iraq

\section{Practicing personal protective measure inside and outside home for health care worker in Nineveh health directorate $-\mathbf{2 0 2 0}$}

\author{
Dr. Marab Younis Abdullah Al-Fathy, Dr. Muna Muneer Ahmed and \\ Dr. Nahla Khalaf Ali
}

DOI: $\underline{\text { https://doi.org/10.22271/27069567.2021.v3.i2i.303 }}$

\begin{abstract}
Background: Healthcare provider are most vulnerable group to contract COVID-19, the importance of follow up instruction for usage with implementation of health education and training on how to put on and take off personal protective equipment to protect them self and their families.

Aim: To assess practice of health care worker toward using personal protective measure inside and outside home against COVID-19.

Persons and Methods: A cross sectional study among 1290 health care worker in Nineveh Health Directorate was carried out for six-month duration, using electronic data collection form, consist from three-part socio-demographic characters and personal protective measure inside and outside home against COVID-19. Three-point Likert-scale and the mean score was calculated.

Result: $70 \%$ of participant their age between $25-45$ years, $57.9 \%$ was male, $79.3 \%$ married, $52.4 \%$ had university education, $40.1 \%$ medical staff, $56.2 \%$ were working in hospital. The grand mean assessment of practicing protective measure inside and outside home were 1.7 and 1.4 respectively, the (cut-off point $=2$ )

Conclusion: Level of practicing protective measure inside and outside home among health care worker in Nineveh Health Directorate was low in spite of conducting the study among well-educated, employed, healthy middle age worker with good socio-economic condition.
\end{abstract}

Keywords: COVID-19, personal protective measure, health care worker

\section{Introduction}

Coronavirus is a single-stranded RNA virus known as Coronaviridae, this type of virus are known to be zoonotic ${ }^{[1]}$. Causing emerging respiratory infection that was first discovered in December 2019, in Wuhan city, Hubei Province, China ${ }^{[2]}$. The World Health Organization 26 Feb. 2020, announced that the pandemic of coronavirus, as it is recognized in 34 countries, with a total of 90,870 laboratory-confirmed cases and over 3,000 deaths worldwide ${ }^{[3]}$. Causing different symptom such as fever, cough, myalgia, fatigue, headache, chest pain, sometime epigastric pain, diarrhea, loss of appetite and vomiting ${ }^{[4]}$, ranging from mild to severe symptom ${ }^{[5]}$. The increasing spread of the disease causing fear, anxiety, and panic amongst the community, especially for healthcare provider, as the most vulnerable group at risk of contracting this new disease ${ }^{[6]}$. dissemination of the disease in health and social institutions was very high at the same time low level availability of vaccines, little evidence on the effectiveness of potential therapeutic agents and no pre-existing immunity among population against the new coronavirus so that everyone in the population is assumed to be susceptible to the disease ${ }^{[7]}$. In the presence of shortage of life saving equipment with highly contagious disease WHO April 2020, recommended on the importance of follow up instruction to strictly application usage with implementation of health education and training on how to put on and take off personal protective equipment among health care worker ${ }^{[8]}$. Good knowledge can change attitude and improve practice as study among Nigerian health care worker 2020, revealed that low practicing of usage of personal protective equipment due to lack of knowledge ${ }^{[9]}$. To protect our body very important should practice five protective measure which is recommended by WHO (hand hygiene, social distancing measures, avoiding touching the eyes, nose and mouth, respiratory etiquette, and self-isolation) ${ }^{[10]}$. good food practices and handling are always recommended, keep on of social distance at 
least one meter, precaution on shopping, follow instruction ongoing home to minimize the risk of contamination and prevent spread of the disease ${ }^{[5,11]}$. The aim of present study to assess the usage of health care to personal protective measure on going home and shopping to fight against COVID-19 in Mosul city.

\section{Persons and Methods}

All work is approved by the ethical and scientific committee of Nineveh Health Directory / MOH / Iraq by licenses' number (210) in date (10-1-2021). data were collected online, via a self-reported questionnaire, using google drive form to distribute the questionnaire and a link was shared to WhatsApp and Facebook groups of HCWs. The link was also shared personally to HCWs in the contact lists of the investigators, as it was not feasible to conduct a populationbased survey at this time, Across sectional study design was carried out in Nineveh Health Directorate Institution (hospital, PHCCs, department of Nineveh Health Directorate and specialized centers) among 1290 health care worker including doctors, pharmacists and nurses during period extended for six months from $1^{\text {st }}$ Aug. $2020-1^{\text {st }}$ March 2021, using self-reported electronic collection form consist from three part

Part I- Socio-demographic characters consist from 6 items include age group in years $(<25,25-35,35-45,45-55$ and $\geq$ 55), sex (male, female), marital status (single, married, widow and divorce), educational status (primary, secondary, university and higher education), occupational title (medical, para medical, administrative and others), place of working (center of office, hospital, PHCCS, specialist PHCCs)

Part II- Practicing personal protective measures inside home consist from 11 items include the following : I put a red line at the entrance to the house for shoes and non-sterile things, I put a container outside the door of the house to put my mobile device, money wallet, keys and the like before entering the house, and I do not bring them into the house except after sterilization, I take off my outerwear before entering the house, I put a covered container outside my entrance door to put my mask and rubber gloves on it, sterilize clothes (by hairdressing, washing, or ironing) or both, I do not receive any guests, I do not go out unless necessary, and if I have to go out, it is only once a week, I put a sterilization spray at the entrance to the house to sterilize the hands upon entry, I consider the door to the house the line of insulation for my family, stay home, before touching anything, start by washing hands with water and liquid soap for a period of (20) seconds, after which I sterilize with a sterile substance everything that I touched with my hand before washing them.

Prat III- Practicing personal protective measures outside home consist from 4 items as follow: If one of the shopper's sneeze get out of the place, leave a distance of one and a half meters between me and the closest person, if a shopper sneezes do not touch (my nose, mouth and eyes) before I wash my hands and face with soap and water, Ongoing shopping always I put on a mask and gloves.

Statistical Analysis: The information regarding each participant was transferred into a code sheet. data were tabulated, categorized, and analyzed using SPSS (version 26) software program. simple percentage was used. The answer of part II and III was scaled according to three-point Likert-scale as (yes, some of time, and no), the mean score was calculated as follows: (no. of participant said Yes $\times 3+$ no. of participant said sometime $\times 2+$ no. of participant said No $\times 1) / 1290$ which is the total no. of sample size. the deviation of the score using the following formula: cut-off point $(3+2+1) / 3=2$.

\section{Result}

Table 1: Distribution of study sample according to sociodemographic characters

\begin{tabular}{|c|c|c|}
\hline Category & \multicolumn{2}{|c|}{ Total No. $=1290$} \\
\hline Age groups & NO. & $\%$ \\
\hline$<25$ & 55 & 4.3 \\
\hline $25-35$ & 446 & 34.6 \\
\hline $35-45$ & 457 & 35.4 \\
\hline $45-55$ & 246 & 19.1 \\
\hline$\geq 55$ & 86 & 6.7 \\
\hline \multicolumn{3}{|l|}{ Sex } \\
\hline Male & 747 & 57.9 \\
\hline Female & 543 & 42.1 \\
\hline \multicolumn{3}{|l|}{ Marital status } \\
\hline Single & 220 & 17.1 \\
\hline Married & 1024 & 79.3 \\
\hline Widow & 35 & 2.7 \\
\hline Divorce & 11 & 0.9 \\
\hline \multicolumn{3}{|l|}{ Education status } \\
\hline Primary & 20 & 1.6 \\
\hline Secondary & 282 & 21.8 \\
\hline University & 676 & 52.4 \\
\hline Higher education & 312 & 24.2 \\
\hline \multicolumn{3}{|l|}{ Occupational title } \\
\hline Medical staff & 517 & 40.1 \\
\hline Para medical & 467 & 36.2 \\
\hline Administrative & 222 & 17.2 \\
\hline Others & 84 & 6.5 \\
\hline \multicolumn{3}{|l|}{$\begin{array}{ll}\text { Place of Working } \\
\end{array}$} \\
\hline Nineveh Health Center and its departments & 262 & 20.3 \\
\hline Hospital & 725 & 56.2 \\
\hline PHCCs & 146 & 11.3 \\
\hline Specialist PHCCs & 157 & 12.2 \\
\hline
\end{tabular}

Table (1) revealed that $70 \%$ of participant their age between 25-45 years, $57.9 \%$ was male, $79.3 \%$ married, $52.4 \%$ had university education, $40.1 \%$ medical type of occupation, $56.2 \%$ were working in hospital.

Table 2: Percentage of health care worker who practicing personal protective equipment in side home to fight against COVID-19

\begin{tabular}{|c|c|c|c|c|}
\hline Category & $\%$ of Yes & $\begin{array}{c}\% \text { of Some } \\
\text { time }\end{array}$ & $\%$ of $\mathrm{No}$ & $\begin{array}{c}\text { Mean } \\
\text { assessment }\end{array}$ \\
\hline 1- I put a red line at the entrance to the house for shoes and non-sterile things & 45.7 & 20.4 & 33.9 & 2.11 \\
\hline $\begin{array}{l}\text { 2- I put a container outside the door of the house to put my mobile device, money wallet, keys } \\
\text { and the like before entering the house, and I do not bring them into the house except after } \\
\text { sterilization }\end{array}$ & 43.4 & 24.5 & 32.1 & 2.11 \\
\hline 3- I take off my outerwear before entering the house & 35.5 & 26.6 & 37.9 & 1.97 \\
\hline
\end{tabular}




\begin{tabular}{|c|c|c|c|c|}
\hline 4- I put a covered container outside my entrance door to put my mask and rubber gloves on it & 30.4 & 21.2 & 48.4 & 1.81 \\
\hline 5- Sterilize clothes (by hairdressing, washing, or ironing) or both & 24.9 & 25.5 & 49.6 & 1.75 \\
\hline 6- I do not receive any guests & 24.3 & 44.3 & 31.5 & 1.92 \\
\hline 7- I do not go out unless necessary, and if I have to go out, it is only once a week & 20.2 & 35.6 & 31.5 & 1.63 \\
\hline 8- I put a sterilization spray at the entrance to the house to sterilize the hands upon entry & 18.3 & 18.8 & 62.9 & 1.55 \\
\hline 9- I consider the door to the house the line of insulation for my family & 17.1 & 20.8 & 62.1 & 1.55 \\
\hline 10- Stay home & 14.6 & 41.7 & 43.7 & 1.70 \\
\hline $\begin{array}{l}\text { 11- Before touching anything, start by washing hands with water and liquid soap for a period } \\
\text { of (20) seconds, after which I sterilize with a sterile substance everything that I touched with } \\
\text { my hand before washing them. }\end{array}$ & 9.5 & 22.1 & 68.4 & 1.41 \\
\hline
\end{tabular}

Percentage of health care worker who practicing personal protective equipment in side home against COVID-19 was seen in (Table 2). I put a red line at the entrance to the house for shoes and non-sterile things, I put a container outside the door of the house to put my mobile device, money wallet, keys and the like before entering the house, and I do not bring them into the house except after sterilization rank the tope of list, they were $45.7 \%$ and $43.4 \%$ respectively. Before touching anything, start by washing hands with water and liquid soap for a period of (20) seconds, after which I sterilize with a sterile substance everything that I touched with my hand before washing them reported least items $9.5 \%$. Grand mean assessment for all items in general was $1.78 \%$, it was below the cut- off point $=2$.

Table 3: Percentage of health care worker who practicing personal protective measures outside home to fight against COVID-19.

\begin{tabular}{|c|c|c|c|c|}
\hline Category & $\begin{array}{l}\% \text { of } \\
\text { Yes }\end{array}$ & $\begin{array}{l}\text { \% of Some } \\
\text { time }\end{array}$ & $\%$ of No & $\begin{array}{c}\text { Mean } \\
\text { assessment }\end{array}$ \\
\hline 1 - If one of the shopper's sneezes, get out of the place. & 13.7 & 27.1 & 59.2 & 1.5 \\
\hline 2- Leave a distance of one and a half meters between me and the closest person & 9.8 & 34.2 & 56.0 & 1.5 \\
\hline $\begin{array}{l}\text { 3- If a shopper sneezes, do not touch (my nose, mouth and eyes) before I wash my hands } \\
\text { and face with soap and water }\end{array}$ & 8.9 & 21.6 & 69.5 & 1.3 \\
\hline 4- On going shopping always I put on a mask and gloves & 5.3 & 20.4 & 74.3 & 1.3 \\
\hline \begin{tabular}{|c|} 
Total \\
\end{tabular} & $121(9.4)$ & $333(25.8)$ & $836(64.8)$ & 1.4 \\
\hline
\end{tabular}

Percentage of participant who say if one of the shopper's sneezes, get out of the place $13.7 \%$, Leave a distance of one and a half meters between me and the closest person $9.8 \%$ and ongoing shopping always I put on a mask and gloves $5.3 \%$. The grand mean assessment was 1.4. This is seen in (Table 3).

\section{Discussion}

In Mosul city 2020 March, reported $1^{\text {st }}$ cases of COVID-19 and rapidly spreading all over the governorate and the number of cases is rising within short period, there is a need for immediate action. There are no vaccines available at that time, there is little evidence on the effectiveness of potential therapeutic agents, no pre-existing immunity in the population against the new coronavirus and damaging infrastructure of health institution during Mosul liberation from Daish control resulted in weaknesses of health care systems which cannot cope with a sudden increase in the number of patients who need treatment. The current pandemic is reducing medical resources requires adaptation practicing personal protective equipment to fight against the diseas ${ }^{[7,11,12]}$.

\section{1-Socio-demographic characters and practicing personal protection}

Two third of study sample aged between 25-35 years, male to female ratio nearly equal, three fourth married, $40 \%$ was doctors with different specialty and graduation, three fourth had university and higher education, more than fifty percent of participant working in hospital. It is noticed that most of the sample among young adult because the country's policy is currently delaying the employment of new graduates, and the retirement law has set the age of 60 for the employee in general for all specializations as a result of the financial crisis the country is going through. According central statistical organization 2004, male to female ratio among Iraqi population was $49.7 \%$, [13] in Mosul city 2004, the women constituted $49.8 \%$ of the total population according to $\mathrm{MoH} 2005^{[14]}$. In the present study there is more than one third of study sample were doctors and more than two third were having university and higher education but reported very low level of practicing personal protective measure inside and outside home to fight against COVID-19 as data did not collected during peak of transmission of disease in the community, not all participant were working in emergency department for COVID-19 and the information were collected via a web based survey may be subjected to low reliability and accountability compared to face-to-face interviews, in addition to that there was no formal education program applied to health care worker, the information taken primarily from internet and on personal effort, lack of knowledge is a barrier to practice in general.

\section{2- Practicing personal protection inside and outside home.}

The present study showed only one fourth of participant $332(25.8 \%)$ follow the standard precaution methods in their home this low percent during pandemic of COVID 19 in presence of limited resource in health institution led to wide expanding of disease among health worker and their families and among population in general.

WHO April /2020 recommended on the prevalence of the five personal protective measures was approximately 60$85 \%$ including wearing mask, frequent hand washing, keep away distance at least 1 meter, avoid touching your face, eyes with your hands, keep home if you feel sick, to avoid infection, in addition to that recommended for the rational use of personal protective equipment (PPE) in health care and home care settings, as well as during the handling of cargo to minimize rapid spread of disease and overcome the 
insufficient resources in health system in general ${ }^{[8]}$.

Chinas study 2020, concluded that increasing the input population and decreasing the quarantine strategy together around the time point of the peak value of the confirmed cases, may lead to the second outbreak ${ }^{[15]}$. A similar finding of low practicing protective measure was seen among Nigerian health worker April 2020, using web-based selfadministered questionnaire via a social media network showed that HCWs' knowledge about, attitudes towards, and beliefs on PPE and their practicing PPE were remarkably poor ${ }^{[9]}$. Unlike cross-sectional study was conducted among 1231 Yemeni Health Care Workers (HCWs) showed that had good knowledge toward COVID19, positive attitude regarding pandemic, low anxiety and high behavioral preventive measure in spite of didn't attending educational program regarding COVID-19, this could be attributed to their educational level since most of respondents $(73.0 \%)$ held a bachelor's degree or higher so that the participant had ability to get information from different resources ${ }^{[6]}$. Another finding was seen in survey in Pakistan, the majority of HCWs (414) have good knowledge 386 (93.2\%), a positive attitude (mean 8.43) and good practice $367(88.7 \%)$ towards COVID-19, the participant used social media as their main source of information 363 $(87.68 \%)^{[16]}$. Low implementation of personal protection measure was seen among (2400) Japanese citizen as only $34.7 \%$ implemented all measures during the early phase of COVID-19 outbreak ${ }^{[17]}$. Practicing personal protection methods outside home was very low, the overall percent of adherent to PPE were only $(9.4 \%)$. Wearing gloves and mask (68/5.3\%), keep away distance at least 1 meter (127/ 9.8 ), avoid touching your face, eyes with your hands (115/ $8.9 \%$ ) The finding agreed by study in Japan 2020, among 2400 participant as the frequency of hand hygiene 1405 (58.5), social distancing measures 710 (29.6), avoiding touching eyes, nose and mouth 585 (24.4), self-isolation 665 (27.7) and avoiding places where many people are gathered together was $29.6 \%{ }^{[17]}$, unlike study among general population $(3,388)$ in Saudi Arabia, using data collected via an online self-reported questionnaire, results showed that the participants' knowledge of COVID-19 translates into good practices, during the COVID-19 pandemic, as $95 \%$ of respondents refrained from attending social events, $94 \%$ avoided crowded places, and $88 \%$ avoided shaking hands. This finding attributed to education and provision of outreach materials, educational program via television, news and media platforms resulted increasing population awareness toward COVID-19 ${ }^{[18]}$. In this study only one fourth $121(9.4 \%)$ of participant practicing personal protective measure on go to shopping, this low percent in spite of starting a wide educational program across the city implemented by health promotion unite/ department of public health to encourage health worker and population to follow the WHO recommendation to fight against COVID 19 , this neglection due to the un acceptance and denial of the people in Mosul city to the presence of such disease due to past history and facing bad condition under Daish control. Denial is one method of mind protection on crises practice it to overcome the problem [19]. A study in Pakistan recommended on the importance of wash vegetables and fruits before eating, wash, rinse, and disinfect objects and surfaces every time before and after use, keep cooked and raw foods separate, use different chopping boards and utensils for cooked and raw foods, wearing gloves during preparing food and frequently disinfect surfaces which came in contact with customers or workers to minimize risk of cross infection ${ }^{[20]}$. Although WHO 2020, reported the potential for contamination of commercial goods by an infected person is low [5, 10]. University Mosul /Dental collage recommended in their guideline to the important of the follow protective activity on going for shopping such as wear mask and gloves, disinfect and clean goods before consumption, disinfection of hands when entering and leaving the shopping center, sterilize baskets and trolleys before shopping, use of stair instead of elevators and keep social distance at least one meter. ${ }^{11} \mathrm{~A}$ study among 4850 Malaysian participant revealed that $83.4 \%$ of them reported that they were avoiding crowded places, $87.8 \%$ practiced proper hand hygiene by frequently washing their hands and using hand sanitizer, $51.2 \%$. wearing face masks, $(89.9 \%)$ of the participant believe that the ability of Malaysian government to handle the crisis ${ }^{[21]}$. Also a study of online KAP questionnaire was completed by 6919 Chinas participants, the vast majority of the participants had not visited any crowded place $(96.4 \%)$ and wore masks when going out $(98.0 \%)$. Nearly all of the respondents $(97.1 \%)$ had confidence that China can win the battle against COVID-19 ${ }^{[22]}$.

Limitation: we can't generalize the study to whole population as study carried out among highly educated, employed, had good socio-economic status, urban residence and middle age group in presence of limited epidemiological information regarding (efficiency of different modes of transmission, proportion of mild and asymptomatic cases, transmission during incubation and recovery period, effectiveness of treatment regimes, risk factors for severe illness besides age and effective preventive measures).

Conclusion: Level of practicing protective measure inside and outside home among health care worker in Nineveh Health Directorate was below the cut-off point in spite of conducting the study among well-educated, employed, healthy middle age worker with good socio-economic condition.

\section{Recommendation}

1- Wide expanding survey and study to include who sector in the community due to

2- Repeat study to include civilian population of low socioeconomic status, unemployment, less educated, those who live in villages faraway from center of the Mosul city.

3- Application of the formal education program through distribution of educational material via social media and /or TV. program to improve knowledge and enhance practice.

Conflicts of Interest: The authors declared no potential conflicts of interest with respect to the research, authorship, and/or publication of this article.

Acknowledgements: The authors thank all the participants involved in this study for their cooperation and support.

\section{References}

1. Gorbalenya AE, Baker SC, Baric RS, De Groot RJ, 
Drosten Ch, Gulyaeva AA, et al. The species severe acute respiratory syndrome related coronavirus: classifying 2019-nCoV and naming it SARS-CoV-2. Nat Microbiol. 2020;5:536-544.

2. Wu F, Zhao S, Yu B, Chen YM, Wang W, Song ZG, et al. A new coronavirus associated with human respiratory disease in China. Nature. 2020;579(7798):265-9.

3. Sohrabia C, Alsafib Z, O'Neilla N, Khanb M, Kerwanc A, Al-Jabir A, et al. World Health Organization declares global emergency: A review of the 2019 novel coronavirus (COVID-19). International Journal of Surgery. 2020;76:71-76.

4. Al-Ajwady AD. guideline of home healthy isolation of COVID- 19 patient. $4^{\text {th }}$ edition. Basrah-Iraq: Dar AlAmal; 2020, 1-48.

5. WHO. Novel COVID -19 Guideline [online 1 Mar 2020]. Cited[20 Nov. 2020] available from WHO:URL; http://www.emro.who.int/ar/health-topics/coronavirus/information-resources.html.

6. Alrubaiee GG, Al-Qalah TA, Al-Aawar MS. Knowledge, attitudes, anxiety, and preventive behaviors towards COVID-19 among health care providers in Yemen: an online cross-sectional survey. BMC Public Health. 2020;20:1541-1552.

7. European Centre for Disease Prevention and Control (ECDC). Novel coronavirus disease 2019 (COVID-19) pandemic: increased transmission in the EU/EEA and the UK [online 12 Mar 2020]. Cited[20 Nov. 2020]. Stockholm: ECDC; 2020. sixth update. [A report].

8. WHO. Rational use of personal protective equipment for coronavirus disease (COVID-19) [online 22 Mar 2020]. Cited[20 Dec. 2020]. URL; https://apps.who.int/iris/handle/ 10665/331498 (accessed 22.03.20).

9. Alao MA, Durodola AO, Ibrahim OR, Asinobi OA. Assessment of health workers' knowledge, beliefs, attitudes, and use of personal protective equipment for prevention of COVID-19 infection in low-resource settings. Advances in Public Health 2020: [10]screen.

10. WHO. Basic protective measures against the new coronavirus [online 22 Mar 2020]. Cited [2 Jun. 2020]. URL; https://www.who.int/emergencies/diseases/novelcoronavirus-2019/advice-for-public.

11. Atar Bashi RS. Novel COVID-19 guideline. Mosul: Mosul University/ Collage of Dentist, 2020, 17-20.

12. Smereka J, Szarpak L. The use of personal protective equipment in the COVID-19 pandemic era. The American journal of emergency medicine. 2020 Apr 15.

13. Central Statistical Organization. Results of the General Population Census 1997 [booklet]. Baghdad: Ministry of Planning, 2004, 43-45.

14. Resource Management Department. Statistical forms for primary health care centers for women of childbearing age 2004-2005 [Brochure]. Baghdad: Ministry of Health and Environment, 2005, 1-5.

15. Hu Z, Cui Q, Han J, Wang X, Wei EI, Teng Z. Evaluation and prediction of the COVID-19 variations at different input population and quarantine strategies, a case study in Guangdong province, China. International Journal of Infectious Diseases. 2020;95:231-2409-

16. Saqlain M, Munir MM, Rehman SU, Gulzar A, Naz S, Ahmed Z, et al. Knowledge, attitude, practice and perceived barriers among healthcare workers regarding
COVID-19: A cross-sectional survey from Pakistan. Journal of Hospital Infection. 2020;105(3):419-23.

17. Machida M, Nakamura I, Saito R, Nakaya T, Hanibuchi $\mathrm{T}$, Takamiya $\mathrm{T}$ et al. Adoption of personal protective measures by ordinary citizens during the COVID-19 outbreak in Japan. International Journal of Infectious Diseases, 2020.

18. Al-Hanawi MK, Angawi K, Alshareef N, Qattan AMN, Helmy HZ, Abudawood Y, et al. Knowledge, attitude and practice toward COVID-19 among the public in the kingdom of Saudi Arabia: a cross-sectional study. Front Public Health. 2020;8(217):1-10.

19. Youzbaki DB. Cultural sociology for health and illness: introduction to psychology. Mosul: Dar Ibn Al-Atheer Press, 2007, 59-75.

20. Aman F, Masood S. How nutrition can help to fight against COVID-19 pandemic. Pak J Med Sci. 2020;36:S121-S123.

21. Azlan AA, Hamzah MR, Sern TJ, Ayub SH, Mohamad E. Public knowledge, attitudes and practices towards COVID-19: a cross-sectional study in Malaysia. PLoS ONE. 2020;15(5):e0233668.

22. Zhong BL, Luo W, Li HM, Zhang QQ, Liu XG, Li WT. Knowledge, attitudes, and practices towards COVID-19 among Chinese residents during the rapid rise period of the COVID-19 outbreak: a quick online cross-sectional survey. Int. J Biol. Sci. 2020;16(10):1745- 1752. 